\title{
FATAL CORONARY THROMBOSIS IN A MAN AGED TWENTY-TWO
}

\author{
BY \\ W. SLOAN MILLER AND W. W. WOODS \\ From the Laboratory, R.N. Hospital, Haslar, and the Bernhard Baron Institute of Pathology, the London Hospital \\ Received October 30, 1942 \\ We have been able to find only two cases of coronary thrombosis in young adults pub- \\ lished in this country (Fernando, 1935, and Blaze, 1937). Both were reported from Ceylon, \\ and the following case of coronary thrombosis in a man aged twenty-two in this country is \\ therefore thought worthy of record.
}

\section{CASE REPORT}

C. A. S., a leading air mechanic, died suddenly at the age of 22 years and 4 months. He was dead before medical attention could be given, and the following history was obtained from relatives, friends, and Service medical records.

There was no family history of circulatory or other relevant disease. Three of his grandparents died in old age; his fourth grandparent, both his parents, and his two siblings were alive and well.

Apart from measles in childhood, influenza five years before his death, and occasional common colds for which he required no medical attention, he had had no illness. He had always led an active life, swimming and cycling and playing cricket and football. He seldom drank alcohol and smoked about ten cigarettes a day. He was a clerk in civilian life and joined the Navy over three years before his death. During this period his medical records show that he served in several different shore establishments without illness of any kind, and that he was always found fit at routine medical examinations.

A comrade who had been his close companion in the Navy for the last two years of his life supplied the following details. C. A. S. appeared to be normal and healthy in every way and never complained of pain, breathlessness, or any other symptoms. On the evening before his death they had a meal ashore together and went to bed at their usual time. Nothing untoward happened during the night. They got up as usual at 6.45 the next morning and the patient then appeared quite normal. Half an hour later he complained of "feeling queer," but carried on working (bed-making). He did not appear to be particularly ill, but about an hour after first complaining he suddenly collapsed on the floor. He was placed on his bed, where it was noticed that his respirations were slow and sighing and that he was very pale. Breathing stopped a few minutes later, and when he was examined by a doctor shortly afterwards he was found to be dead.

\section{Summary OF NeCropsy AND OF Microscopical Findings}

A well-nourished young man of good physique, with no external evidence of injury or disease. Left coronary artery $(0.9 \mathrm{~cm}$. long) normal. Lumen of first $4.5 \mathrm{~cm}$. of anterior descending branch of left coronary occluded by firm, grey, completely organized, canalized 
thrombus, fused with a slightly fatty atheromatous hypertrophied intima. Remainder of anterior descending branch normal except for slight hypertrophy of intima. Considerable stenosis by atheroma, and occlusion by organizing thrombus of first $0.5 \mathrm{~cm}$. of circumflex branch of left coronary artery, and slight stenosis by atheroma, $1 \mathrm{~cm}$. from its origin. Circumflex branch abnormally short, ending as the left marginal artery. Numerous minute flecks of fatty atheroma and one larger atheromatous area $(0.4 \times 0.3 \mathrm{~cm}$.) in right coronary artery, without stenosis of lumen. No recent coronary thrombosis found. Coronary sinus and its tributaries normal. Numerous, irregularly branched, white areas of ischæmic fibrosis of myocardium in middle third of interventricular septum, the largest being $1 \times 0.4 \mathrm{~cm}$; few in lower third; none elsewhere in myocardium. No recent infarction of myocardium detected. No enlargement of heart (weight $12 \mathrm{oz}$.). Pericardium and cardiac valves normal. Numerous very small flecks of fatty atheroma in first $2 \mathrm{~cm}$. of aorta, a few in aortic arch and a few, accompanied by sparse faint streaks of fatty atheroma, in descending aorta. Congestion of kidneys. Slight congestion of liver. One pint of semi-digested food in stomach. No abnormality found in brain, mouth, air passages, lungs, or any other organ.

Microscopical Description. In sections of the anterior descending branch at the upper end of the occluded area, the lumen is filled with a tissue composed of fibroblasts, collagen fibres, a few macrophages containing pigment and giving a positive reaction for iron, numerous capillaries and numerous vessels with walls composed of thick layers of involuntary muscle fibres and elastic fibres; most of these well-developed vessels lie near the intima and have very narrow lumina. In sections $2 \mathrm{~cm}$. further down the artery the canalizing vessels have wider lumina and their walls contain less muscle but abundant elastic fibres. In both sets of sections the intima is hypertrophied, having developed a thickened longitudinal musculo-elastic layer between the elastic lamella and the elastic stripe, as well as a hyperplastic elastic layer internal to the latter (Fig. 1). Frozen sections stained with Sudan III show very slight focal fatty atheroma in the hypertrophied intima. The media of the anterior descend-

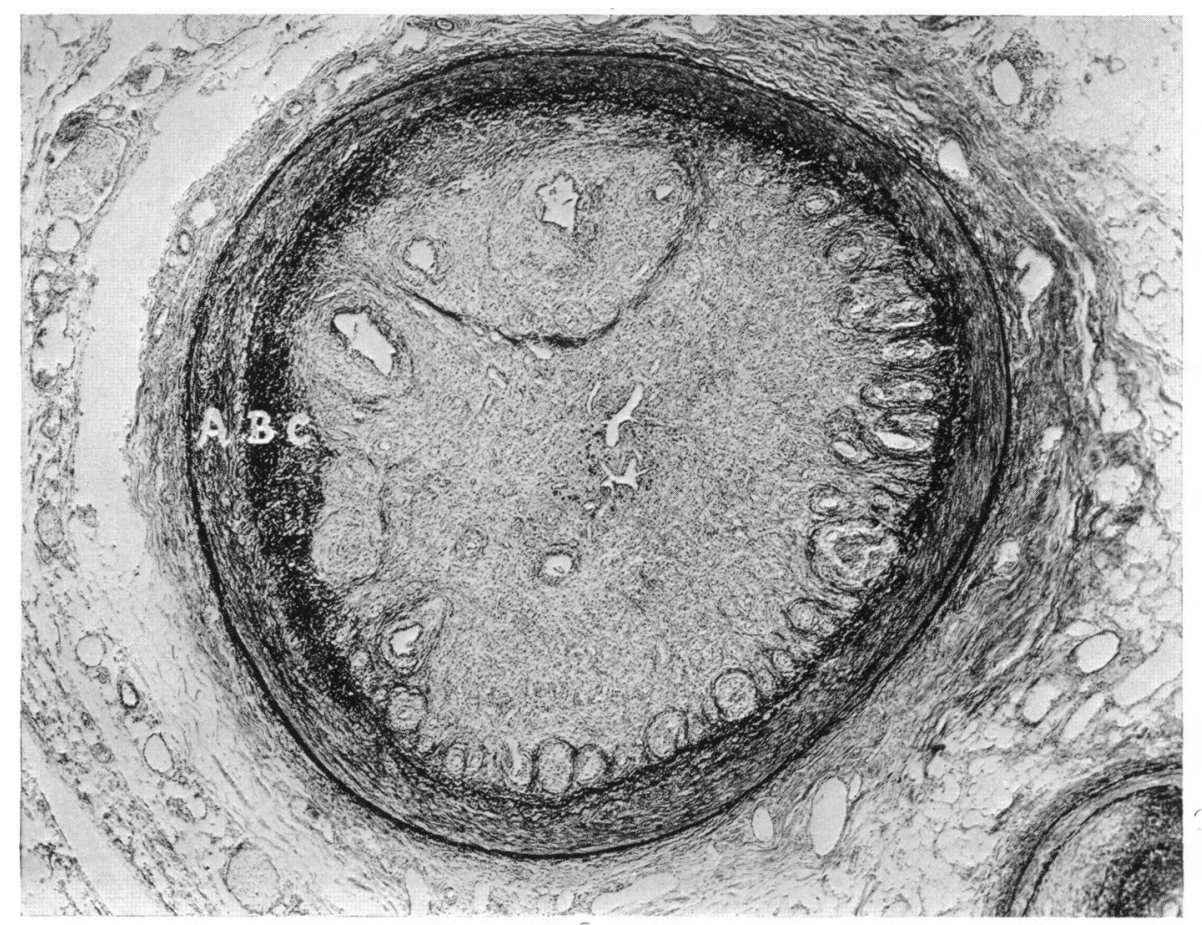

FIG. 1.-Upper part of anterior descending branch, occluded by canalized organized thrombus. $A=$ media. $\mathbf{B}=$ longitudinal musculo-elastic layer of intima. $\quad \mathbf{C}=$ Hyperplastic elastic layer of intima. Weigert's fuchselin and neutral red. $\times 32$.

The section has been overstained in Weigert's fuchselin to make the elastic fibres in the new vessels of the organized thrombus more distinct in the photo; this overstaining has the disadvantage of making the division between layers $B$ and $C$ less distinct, although this division is absolutely clear when the section is examined with the microscope. 
ing branch is normal except that it is unusually rich in elastic fibres. The adventitia is normal except that the small vessels in and outside it are dilated. The neighbouring smaller and larger branches of the artery are normal except that in one of the largest there is slight fibro-musculo-elastic hypertrophy of the intima. The lower half of the anterior descending branch is normal except for slight hypertrophy of the intima, consisting chiefly of proliferated elastic fibres. There is a considerable amount of elastic in its media. Its branches are normal. Two transverse pieces were taken from the first $0.5 \mathrm{~cm}$. of the circumflex branch for paraffin embedding, and one piece for frozen sections. Areas of atheromatous intima, several times thicker than the normal media, bulge into the lumen; these areas have an inconspicuous longitudinal musculo-elastic layer, and consist mainly of a greatly thickened hyperplastic layer which is composed of abundant delicate elastic and collagen fibres and numerous spindle and polygonal macrophages full of fat. The lumen is occupied by a central area of fibrin with a few leucocytes and red blood corpuscles and a broad peripheral zone of delicate connective tissue composed mainly of fibroblasts and capillaries and containing very few slender collagen fibres and no pigment macrophages. In the adventitia and extra-adventitial connective tissue there is dilatation of capillaries and very slight infiltration with lymphocytes, but nowhere is there any suggestion of acute or chronic arteritis. In a similar series of sections of the circumflex branch, taken $1 \mathrm{~cm}$. from its origin, there is a slightly lesser degree of atheroma and no other abnormality. No hæmorrhage and no capillaries were seen in the intima above and at the sides of the areas of atheroma in any of the coronary arteries. In the large pieces of interventricular septum included in these sections there is much old ischæmic destruction of myocardium, showing as numerous areas of muscle replaced by dense fibrous tissue which is remarkably rich in elastic fibres. There is no fatty degeneration of the myocardium to be seen in frozen sections of the interventricular septum stained with Sudan III. The largest coronary branch in the myocardium in these sections has its lumen obliterated by a tissue similar to that described in the occluded part of the anterior descending branch; this tissue is fused with the hypertrophied intima, which consists chiefly of elastic fibres.

Congestion is conspicuous in sections of the kidney, but there is no other abnormality. Congestion is less obvious in the liver.

\section{DisCUSSION}

The incidence of coronary thrombosis before the fifth decade varies according to different authors. White and Mudd (1927) found 3 per cent of 418 cases under 40; Conner and Holt (quoted by Reitman et al., 1942) in a series of 287 cases found 8 per cent under 40 and 1 per cent under 30 . Durant, 1937, in his 114 cases of proved coronary thrombosis reported 7 (6 per cent) under the age of 35, only 1 of which was under 30 .

Scott (1938) was able to collect a total of 208 cases of coronary thrombosis in patients under 40; of these only 28 were aged 30 or less. Reitman et al. (1942), found 34 reported cases below 30 , and 4 below 20 years of age, among their total collection of 221 cases under 40 .

Although arteriosclerosis has been found in children as young as two years (Stolkind, 1928) and cases of coronary calcification and thrombosis have been reported in infancy, the pathogenesis in these appears to be little related to the accident occurring in later life; thus Brown and Richter (1941) suspect some alteration in the calcium and phosphorus metabolism, and in van Crevald's (1941) case of coronary thrombosis in a girl 7 weeks old, the disease appeared to be related to the use of drugs by the allergic mother.

Apart from infancy, the youngest reported case of coronary thrombosis appears to be at the age of 12 (Dreschfeld and Benda, quoted by Smith and Bartels, 1932). Sprague and Orgaine (1935) describe two cases at 15 and 16 years, proved at necropsy. In the remainder of the published cases of coronary thrombosis in young adults the condition occurs with increasing frequency from the age of 18 upwards.

Coronary thrombosis is so commonly associated with men in their fifties or sixties that its occurrence in young adults might be thought to differ in some essential way from the typical case in later life. Syphilitic aortitis, for example, is sometimes considered a relatively frequent cause under the age of 40; but in the cases reported under the age of 30 it appears to play no part. Since Barron and Linenthal (1929) described thrombo-angiitis obliterans as a cause of coronary thrombosis, it might be expected that this disease would account for at least some of the cases of coronary thrombosis in young adults, but again there is no reported evidence of this.

Herapath and Perry (1930) have reported a family remarkable for the early age at which there were sudden deaths of four different members, and this is probably an important factor 
in the occurrence of cases early in life. The father died suddenly of heart disease when 42 . There were nine children, of whom three sons died suddenly from heart disease, each at an early age. The second son died at 30 . The fifth son, aged 32 , was taken ill when playing football and died within an hour, his heart showing gross atheromatous changes in the coronary arteries. The eldest son, then aged 39, was already complaining of a tight feeling in his chest when he hurried or took any exercise. Four years later the attacks were worse, and were associated with severe anginal pain even on quiet walking. The heart was not enlarged, and the cardiogram, which had been normal two years before, now showed inversion of the $\mathrm{T}$ waves in leads II and III. A month later he fell dead while getting into a tram. There were atheromatous changes in the thoracic and abdominal aorta with ulceration and some calcification, the media showing replacement fibrosis and the intima showing extensive fatty degeneration. The coronary arteries were hard and thickened, and after injection showed the increase of vascularity corresponding to an extreme degree of the "age change" described by Gross as occurring in a man of over sixty.

The following eleven cases of coronary thrombosis at the age of 30 and under have been abstracted; in the other published cases either the data given are insufficient for comparative purposes or the original papers were not available.

1. Fernando (1935) reported the case of an athletic male Cingalese, aged 24, who had attacks of anginal pain with dyspnœa, occurring first while in bed. An electrocardiogram (EC.) confirmed the diagnosis of coronary thrombosis. The patient was discharged from hospital after two months. Wassermann reaction negative. No previous illness. Mother died of heart attack when 45.

2. Durant (1937) reported the case of a male Jewish student, aged 23, who had three attacks of substernal pain with dyspnœa before admission to hospital. EC. confirmed anterior cardiac infarct. Kahn negative. No relevant family history or previous illness.

3. Blaze (1937) reported a Tamil manual labourer, aged 23, who collapsed on his way to work with symptoms of coronary artery occlusion. He died shortly afterwards and at necropsy an ante-mortem thrombus was found attached to the wall of the beginning of the descending branch of the left coronary artery. Both coronary arteries showed atheromatous plaques. No relevant past history was obtained and family history was not noted.

4. Franklin's (1938) case was an American male, aged 30, who two months before investigation had a sudden attack of severe chest pain lasting two days, and subsequent attacks of less severity. He was a heavy drinker and smoked 20 to 40 cigarettes a day, but had no previous illness except ichthyosis. His mother died, aged 54, of high blood pressure. Kahn negative. EC. was suggestive of myocardial infarction. He gradually improved.

5. Halbersleben (1938) reported the case of a 28 year old American housewife who developed symptoms of coronary artery occlusion while sitting at table. She died five days later, and at necropsy the right coronary artery was found to be occluded by thrombus. Both coronary arteries showed atherosclerotic thickening, and there were extensive areas of infarct necrosis in the myocardium of the left ventricle. She also had a leukæmia, but the white blood count was only 32,000 per c.mm. and the thrombus was not one of white cells. She had a normal pregnancy at the age of 26 . There was no relevant previous illness or family history.

6. Scott's (1938) patient was a cost accountant, aged 27. He had presternal pain of some hours duration seven days prior to investigation. EC. showed coronary occlusion of T III type. He gradually improved. He had chorea at 7 , but no other previous illness. Wassermann negative. He smoked 15 to 20 cigarettes a day, and seldom drank alcohol. His father died of apoplexy when 63; one of his mother's sisters died of diabetes when 59 years old.

7. Goodson and Willius (1939) reported three cases of coronary thrombosis under the age of 30 , but give details of only one. This was a housewife, aged 22 , in the third month of her first pregnancy. She fell from a low porch and sustained a head injury, remaining unconscious until she died 16 hours later. The necropsy findings were an acute infarct of the posterior wall of the right ventricle and a linear infarct of the central portion of the interventricular septum extending from the base to the apex. There was no atherosclerosis of the coronary arteries according to the authors; since petechial hæmorrhages were found in the cortex they were uncertain whether the fall was occasioned by the severe pain of coronary thrombosis or whether the coronary thrombosis occurred as a result of the fall. 
8. Ferguson and Lockwood (1939) published the case of an American truck driver, aged 26, who was afflicted with substernal and epigastric pain of sudden onset, increasing to maximum severity in 24 hours, radiating to the left shoulder and arm. EC. showed progressive myocardial damage but were not in themselves diagnostic of coronary occlusion; yet a pericardial rub and inversion of $\mathrm{T}$ I indicated a lesion in the anterior and apical region. Wassermann reaction negative. He recovered and was alive and well after six months. He had no previous illness but had used tobacco excessively for years (no amount stated). His father died, aged 40, of cardiovascular disease.

9. Dawber's (1941) case was a man, aged 21, in a Marine hospital who developed symptoms of coronary occlusion, following two 6-hour periods of hyperthermy at $106^{\circ} \mathrm{F}$. for chronic gonorrhœal urethritis. EC. confirmed, showing an anterior infarction. Repeated serological tests for syphilis were negative. The patient survived this attack. He had no other disease. No note of family history is made.

10. Macdonald (1941) reported coronary thrombosis, in a male of 21 , which proved fatal about a year later, in the third attack. No family or previous history is noted. The original attack started while he was walking home after a game of softball, during which he was struck on the chest. The anatomic diagnosis at necropsy was atherosclerosis, stenosis, and thrombosis of the coronary arteries (old thrombosis of the left with recanalization, and recent thrombosis of the right artery); and infarcts of the heart (healed and recent).

11. Reitman et al. (1942) published a case of coronary thrombosis in a student, aged 20, who since the age of 9 had diabetes, which was controlled by diet and protamine insulin at the time of the attack. Past history was otherwise normal. No family history noted. Precordial pressure and dyspnœa on slight exertion began two days after the patient had gone swimming and had to swim some distance to reach the shore. The eyegrounds showed early tortuosity of the vessels with moderate atherosclerotic changes. EC. showed evidence of acute myocardial infarction involving the posterior surface of the left ventricle. The authors ascribe the early onset of coronary thrombosis in this case to hypercholesterolæmia; the blood cholesterol was $350 \mathrm{mg}$. per 100 c.c. The patient survived this attack.

Analysing the above eleven cases along with the one here reported we may observe that in twelve cases of coronary thrombosis between the ages of 20 and 30 :

Ten patients were male and two female (in 27 reported cases of coronary thrombosis under 30 in which the sex was stated, there were only 4 females).

There appeared to be no special predilection for race or occupation.

Four died in the first attack; the remaining eight survived for some months at least.

There was a rheumatic history in only one (Case 6).

Syphilis was not once the cause.

Of seven whose family history is noted, four had evidence of familial " defective tubing."

Atheroma or atherosclerosis was the lesion found in all four cases which came to necropsy and are adequately described. Goodson and Willius' case must be omitted for lack of microscopical data. Scott (1938), referring to his collection of 208 cases of coronary thrombosis under 40, states: "Arteriosclerosis is the pathologic lesion invariably found in all of the cases referred to in this paper that have come to autopsy."

Raised blood pressure was present in only one of the twelve cases (Halbersleben's case; blood pressure about 150/85 for years). Signs of arterial disease, apart from those of coronary occlusion, were absent in these cases.

\section{Summary AND Conclusions}

A case of sudden unexpected death from coronary thrombosis and ischæmic fibrosis of the myocardium is described in a man of twenty-two. Thrombosis had occurred in the anterior descending branch so long before death that the thrombus was completely organized and contained vessels with musculo-elastic walls. There was a more recent incompletely organized thrombus in the circumflex branch. The examination revealed neither a thrombus that had formed immediately before death nor a recent myocardial infarct. The only disease 
found in the coronary arteries predisposing to thrombosis was atheroma. There was no history of any illness before the attack, which started about one hour before death.

2. The reported cases of coronary thrombosis in young adults are reviewed. The condition in young adults is very similar to the typical case in later life except that raised blood pressure has rarely been noted. The pathological lesion found in the cases that have come to necropsy is atheroma (atherosclerosis) of the coronary arteries, the anterior descending branch of the left coronary being most frequently the site of thrombosis.

We are indebted to Surgeon Rear-Admiral Bradbury, C.B.E., D.S.O., for permission to publish this paper.

\section{REFERENCES}

Barron and Linenthal (1929). Arch. Surg. Chicago, 19, 735.

Blaze, J. R. (1937). Brit. med. J., 2, 14.

Brown, C. E., and Richter, I. M. (1941). Arch. Path., 31, 449.

van Crevald, S. (1941). Ann. Paediat., 157, 84.

Dawber, T. R. (1941). Virginia med. Mon., 68, 156.

Durant, T. M. (1937). Ann. intern. Med., 10, 979.

Ferguson, A. S., and Lockwood, J. R. (1939). N.Y. St. J. Med., 39, 1618.

Fernando, P. B. (1935). Brit. med. J., 1, 976.

Franklin, M. S. (1938). J. Mo. Med. Ass., 35, 32.

Goodson, W. H., and Willius, F. A. (1939). Minnesota Med., 22, 291.

Halbersleben, D. (1938). New Engl. J. Med., 218, 175.

Herapath, C. E. K., and Perry, C. B. (1930). Brit. med. J., 1, 685.

Jamison, S. C., and Hauser, C. H. (1925). J. Amer. med. Ass., 85, 1898.

Macdonald, D. (1941). Ibid., 116, 2,846.

May, W. J. (1936). S. Afr. med. J., 10, 772.

Ramsay, R. E., and Crumrine, R. M. (1931). Amer. J. Dis. Child., 42, 107.

Reitman, N., Greenwood, W. R., and Kler, J. H. (1942), Amer. J. med. Sci., 843, 792.

Scott, E. G. (1938). Virginia med. Mon., 65, 391.

Smith, H. L., and Bartels, E. C. (1932). J. Amer. med. Ass., 98, $1,072$.

Smith, H. L., and Hinshaw, H. C. (1937). Amer. Heart J., 13, 741.

Stolkind, E. J. (1928). Brit. J. Child. Dis., 25, 1.

Sprague, H. D., and Orgaine, E. S. (1935). New Engl. J. Med., 212, 903.

White, P. D. (1935). J. med. Soc. N.J., 32, 596.

White, P. D., Glendy, R. E., and Gustafson, P. (1937). J. Amer. med. Ass., 109, 863.

White, P. D., and Mudd, S. G. (1927). Amer. Heart J., 3, 1.

Wright-Smith, R. J. (1936). Royal Melbourne Hosp. Clin. Reports. 